\title{
Design Specifications and Performance analysis of Single and Two Stage HB LLC Converters
}

\author{
A. Jenifer, Y. Sukhi, V. Karthika, A. Fayaz Ahamed
}

\begin{abstract}
In this paper a Single stage and Two stage Half Bridge LLC (HB LLC) converter topologies for DC/DC applications with low input voltage. The basic operation and design procedure for LLC converter is illustrated. Simulation of the proposed converter is done using the design parameters and the results are discussed and then analysis is done to know its performance. The efficiency of the converters is analyzed by MATLAB Software Package.
\end{abstract}

Keywords: Single Stage HB LLC (SS HB LLC),Two Stage HB LLC (TW HB LLC), Resonant Converter.

\section{INTRODUCTION}

At present there are many applications like LED lighting, data centers, automobiles where use of $48 \mathrm{~V}$ has become necessary to a specific application. Power conversion from high voltage level to low voltage has a large range of applications in power distributed generation, energy storage and auxiliary power supplies for train traction systems. First of all, since $48 V_{\mathrm{DC}}$ power supplies are connected in parallel with $48 V_{\mathrm{DC}}$ battery systems, the power system has many strengths such as high reliability and easy maintenance. Therefore, $48 V_{\mathrm{DC}}$ systems are used in many applications. A distributed power network is to be used in an electric vehicle application which is of $48 \mathrm{Vdc}$ distribution network will be used throughout the vehicle [4], [8]-[9].

In view of its simple structure, the single stage power systems with only one topology, for low-to-medium power capability in $48 V_{\mathrm{DC}}$ power systems are extensively applied [4]. Amongst, the single-stage

half- bridge (HB) LLC resonant converter has been widely used because of its advantages like high efficiency at high input voltage, low voltage stress on secondary rectifier. But having wide range of the low input voltage, this converter has design limitations. Since the requirement to operate with a wide input voltage range $\left(36-72 V_{\mathrm{DC}}\right)$ comes from a consideration of the dynamic battery voltage [1], [6]-[9]. The conduction loss in the primary side becomes large in single stage because of reflected current in primary of the

Revised Manuscript Received on November 12, 2019

* Correspondence Author

A. Jenifer, Department of EEE, R.M.K. Engineering College, Kavaraipettai, India. Email: ajr.eee@rmkec.ac.in

Y.Sukhi, Department of EEE, R.M.K. Engineering College , Kavaraipettai, India. Email: ysi.eee@rmkec.ac.in

V. Karthika, Department of EEE, R.M.K. Engineering College, Kavaraipettai, India. Email: vka.eee@rmkec.ac.in

A. Fayaz Ahamed, Department of EEE, R.M.K. Engineering College, Kavaraipettai, India. Email: afd.eee@rmkec.ac.in transformer, thus this converter shows low efficiency. To overcome the design limitation of the single-stage converter, a two stage approach, which consists of the front-end boost converter stage and $\mathrm{dc} / \mathrm{dc}$ output stage was implemented which reduces the conduction losses.

In this paper, the concept and design steps for resonant converters are discussed. Simulation of the converters is done and the comparison of both the converters is done.

\section{CONCEPT AND OPERATIONAL PRINCIPLE OF THE CONVERTERS}

Fig.1(a) shows circuit diagram of Single stage half bridge LLC resonant converter. Without the magnetizing inductance $\mathrm{Lm}$, this converter is the same as series resonant converter. With participation of $\mathrm{Lm}$, the operation and characteristic of the proposed converter is very different from SRC then. Secondary rectifier is used instead of diodes since it provides high efficiency. The circuit has three passive components, $\mathrm{L}_{\mathrm{r}}, \mathrm{C}_{\mathrm{r}}$ and $\mathrm{L}_{\mathrm{m}}$. The secondary side is a center-tapped rectifier followed by a capacitive filter. The primary side of this diagram is a Half Bridge configuration; it could also be full bridge or other topologies. Since there is a capacitor in series with power path, automatic flux balancing can be achieved. In this converter, two resonant frequencies exist. They are the resonant frequency produced due to the inductor $\mathrm{L}_{\mathrm{r}}$ and capacitor $\mathrm{C}_{\mathrm{r}}$, another is the resonant frequency produced by $L_{m}$ plus $L_{r}$ with $C_{r}$. When the applied load is light, the maximum value reaches resonant frequency produced by $\mathrm{L}_{\mathrm{m}}+\mathrm{L}_{\mathrm{r}}$ and $\mathrm{C}_{\mathrm{r}}$. When load becomes heavier, the maximum value of resonant frequency is produced by $\mathrm{L}_{\mathrm{r}}$ and $\mathrm{C}_{\mathrm{r}}$, and gain is unity at resonant frequency $f_{\mathrm{o}}$ and does not dependent on load change. In the proposed converter, MOSFET switches are used as primary switches, so ZVS is preferred [1]-[4], [6]. The current and voltage waveforms of the proposed circuit are shown in Fig 2.

Fig. 1(b) shows circuit diagram of two-stage converter adopting boost converter and LLC resonant converter. The two stage approach, consists of the front-end boost converter stage and dc/dc output stage. By applying the front-end boost converter, $V_{\text {CLINK }}$, which is the input voltage of the resonant converter, can be increased. This converter is used to achieve wide range of input voltage. The waveforms of the proposed converter are shown in Fig 3.MOSFET switches are turned on with ZVS. Since the turn off current is decided by magnetizing inductance $\mathrm{Lm}$, which is not related to load condition, ZVS can be achieved with any load condition. For turn off of MOSFET, turn off current is much smaller than load

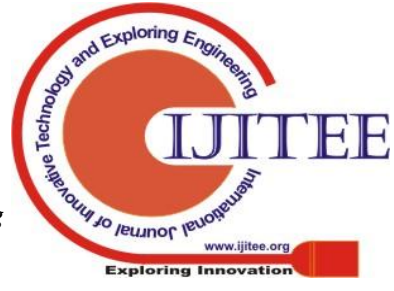


current, so turn off loss can be reduce.

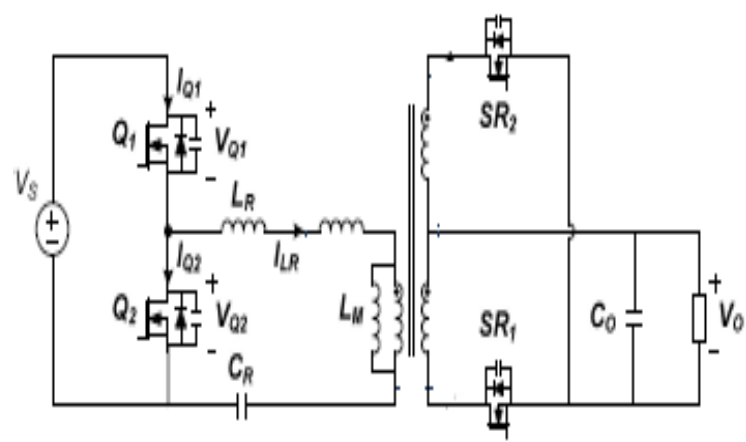

Fig.1. (a) Single stage HB LLC converter (SS HBLLC)

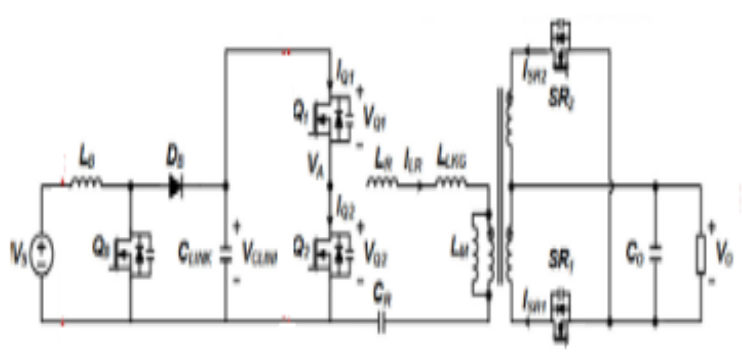

Fig.1. (b) Two stage HB LLC converter (TS HBLLC)

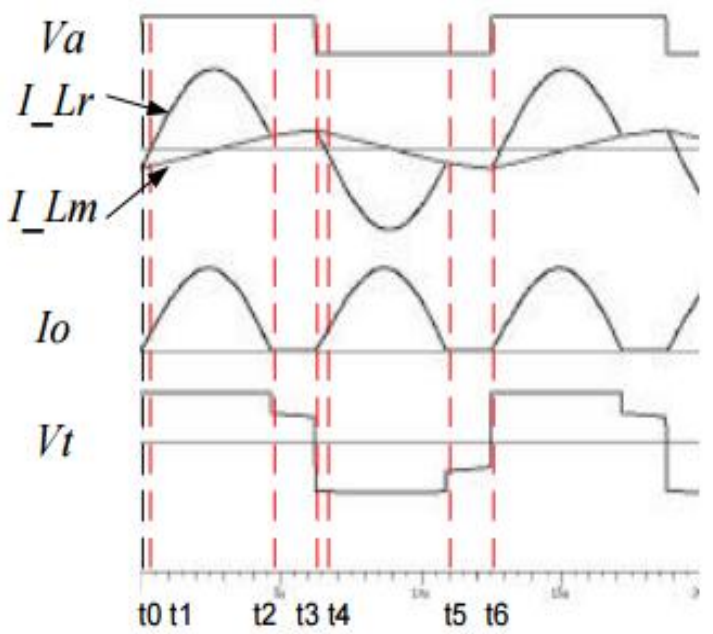

Fig. 2. Waveforms of SS HBLLC

With all these, resonant conditions the switching loss of both the converters are very small.

\section{DESIGN SPECIFICATIONS}

This section demonstrates the step-by-step deign procedure for resonant network design. The converter's electrical specifications are as follows:

Input voltage:36-72 $\mathrm{V}_{\mathrm{DC}}$

Rated output power:300W

Output voltage: $12 \mathrm{~V}_{\mathrm{DC}}$

Rated output current: $25 \mathrm{~A}$

Output-Voltage line regulation $\left(\mathrm{I}_{\mathrm{o}}=1.0 \mathrm{~A}\right) \leq 1 \%$

Output-Voltage load regulation $\left(\mathrm{V}_{\text {in }}=48 \mathrm{~V}\right) \leq 1 \%$
Efficiency $\left(\mathrm{V}_{\text {in }}=48 \mathrm{~V}\right.$ and $\left.\mathrm{I}_{\mathrm{o}}=25 \mathrm{~A}\right) \geq 90 \%$

Switching frequency(normal operation): $33 \mathrm{KHz}$

Resonant frequency $\left(f_{\mathrm{o}}\right)=100 \mathrm{KHz}$

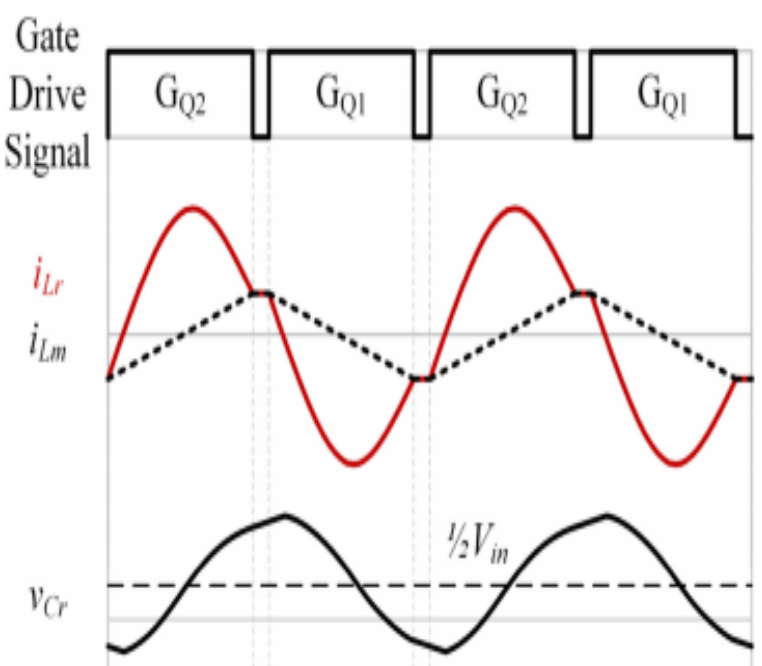

Fig. 3. Current and Voltage Waveforms

\section{A. Determine Transformer Turns Ratio}

The transformer turns ratio is determined by

$$
\begin{aligned}
n & =\frac{\left(V_{\text {in_nom }}\right) / 2}{V_{\text {o_nom }}} \\
& =\frac{48 / 2}{12}=2
\end{aligned}
$$

\section{B. Determine Voltage gain}

$\mathrm{M}_{\mathrm{g} \_ \text {min }}$ and $\mathrm{M}_{\mathrm{g} \_ \text {max }}$ can be calculated using the following equations

$$
\begin{aligned}
M_{g_{-} \min } & =\frac{n \times\left(V_{o_{-} \min }+V_{F}\right)}{V_{\text {in_max }} / 2} \\
& =0.67 \\
M_{g_{-} \max } & =\frac{n \times\left(V_{o_{-} \max }+V_{F}+V_{\text {loss }}\right)}{V_{\text {in_min }} / 2} \\
M_{g_{-} \max } & =\frac{2 \times(12+0.7+1.05)}{36 / 2} \\
& =1.527
\end{aligned}
$$

$\mathrm{V}_{\text {loss }}$ is assumed for voltage drop due to power losses.

\section{Select Inductance $L_{n}$ and Quality Factor $Q_{e}$}

From peak gain curves the values of $\mathrm{L}_{\mathrm{n}}$ and $\mathrm{Q}_{\mathrm{e}}$ are selected as 3.5 and 0.45 .

\section{Determine the equivalent Load resistance}

At full load, Re is calculated as

$R_{e}=\frac{8 \times n^{2}}{\pi^{2}} \times \frac{V_{0}}{I_{0}}$

$R_{e}=\frac{8 \times 2^{2}}{\pi^{2}} \times \frac{12}{25}$

$$
=1.556 \Omega
$$

At $110 \%$ overload,

$R_{e}=\frac{8 \times n^{2}}{\pi^{2}} \times \frac{V_{0}}{I_{0}}$ 


$$
\begin{aligned}
R_{e} & =\frac{8 \times 2^{2}}{\pi^{2}} \times \frac{12}{25 \times 110 \%} \\
& =1.414 \Omega
\end{aligned}
$$

\section{E. Design resonant circuit parameters}

Resonant frequency is selected as $100 \mathrm{KHz}$ and the resonant parameters can be calculated at full load:

$$
\begin{aligned}
C_{r} & =\frac{1}{2 \pi \times Q_{e} \times f_{0} \times R_{e}} \\
C_{r} & =\frac{1}{2 \pi \times 0.45 \times 100 \times 10^{3} \times 1.556} \\
& =22.8 \mathrm{nF} \\
L_{r} & =\frac{1}{\left(2 \pi \times f_{0}^{2}\right) C_{r}} \\
L_{r} & =\frac{1}{\left.\left(2 \pi \times 100 \times 10^{3}\right)\right)^{2} \times 22.8 \times 10^{-9}} \\
& =8.1 \mu \mathrm{H}(\text { approximated to } 10 \mu \mathrm{H}) \\
L_{m} & =L_{n} \times L_{r} \\
L_{m} & =3.5 \times 10 \mu \mathrm{H} \\
& =35 \mu \mathrm{H}
\end{aligned}
$$

\section{F. Verify the Resonant-circuit design}

Series Resonant Frequency

$$
\begin{aligned}
f_{0} & =\frac{1}{2 \pi \times \sqrt{L_{r} \times C_{r}}} \\
f_{0} & =\frac{1}{2 \pi \times \sqrt{10 \mu \times 22.8 \mathrm{n}}} \\
& =105.45 \mathrm{KHz}
\end{aligned}
$$

Inductance Ratio

$$
\begin{aligned}
\mathrm{L}_{\mathrm{n}}= & \mathrm{L}_{\mathrm{m}} / \mathrm{L}_{\mathrm{r}} \\
& =35 \mu \mathrm{H} / 10 \mu \mathrm{H} \\
& =3.5 \mu \mathrm{H}
\end{aligned}
$$

\section{SIMULATION RESULTS}

Simulation models of both converters were built with MATLAB package. For the same design values of resonant components and switching frequency both the converters are simulated and the waveforms are observed. Fig.4 and Fig.5 show the simulation circuit of Single Stage HB LLC converter and two Stage HB LLC converter respectively.

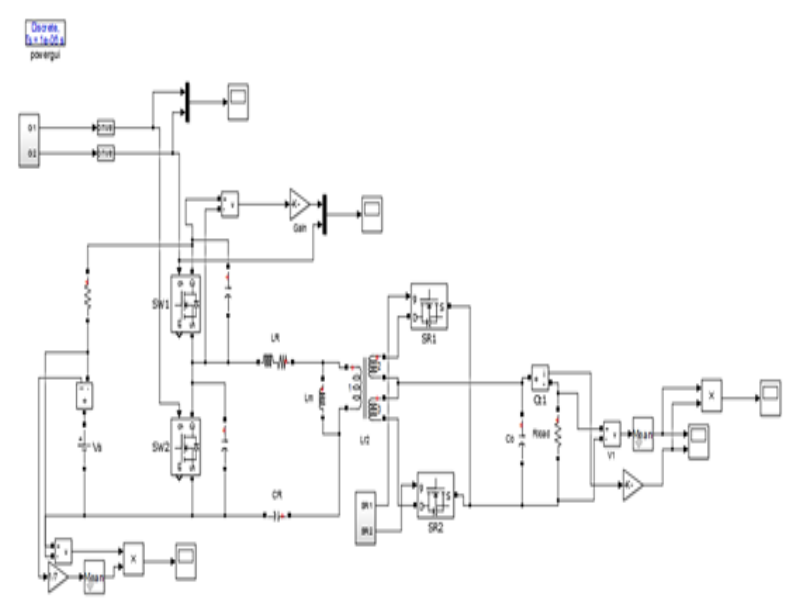

Fig. 4. Simulation circuit of SS HB LLC converter

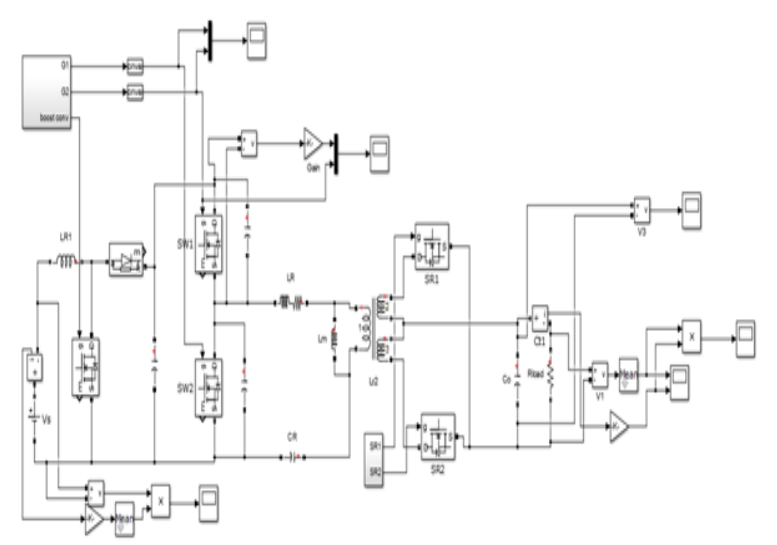

Fig. 5. Simulation circuit of TW HB LLC converter

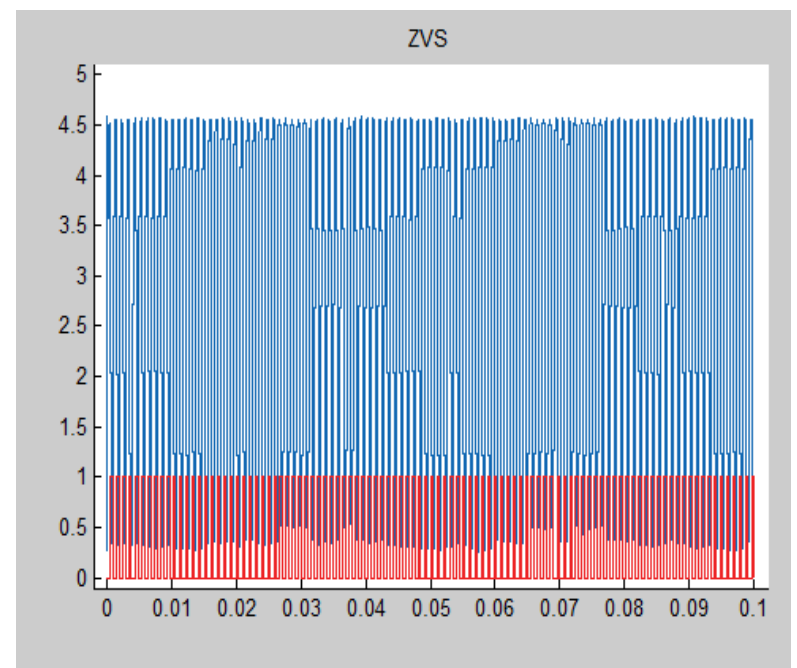

Fig. 6. ZVS of SS HBLLC converter

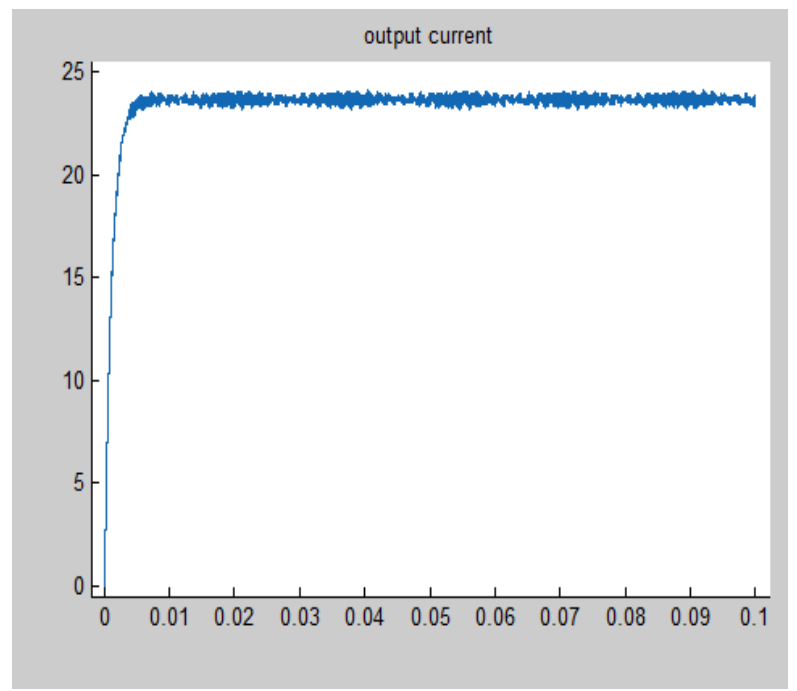

Fig. 7. (a) Output current waveform Waveforms of SS HBLLC

For an input voltage of $\mathrm{V}_{\text {in }}=36$ to $72 \mathrm{~V}\left(\mathrm{~V}_{\text {nom }}=48 \mathrm{~V}\right)$, Switching frequency $f_{s}=33 \mathrm{KHz}$, Resonant frequency $f_{o}=$ $100 \mathrm{KHz}$ at full load is simulated. It is observed from the SS 


\section{Design Specifications and Performance analysis of Single and Two Stage HB LLC Converters}

HBLLC, the current waveform is highly asymmetrical at high input voltage and hence it is used for wide input range because the efficiency is less $88 \%$ can only achieved. The conduction loss is also high. But the TS HBLLC waveforms show that it can cover wide input range and with high input voltage it gives an efficiency of $93 \%$ which is $5 \%$ improvement from the former and the conduction loss is also less. Fig 6 shows the ZVS. Fig 7 (a) and (b) shows the output current and voltage waveforms of HB LLC converter.

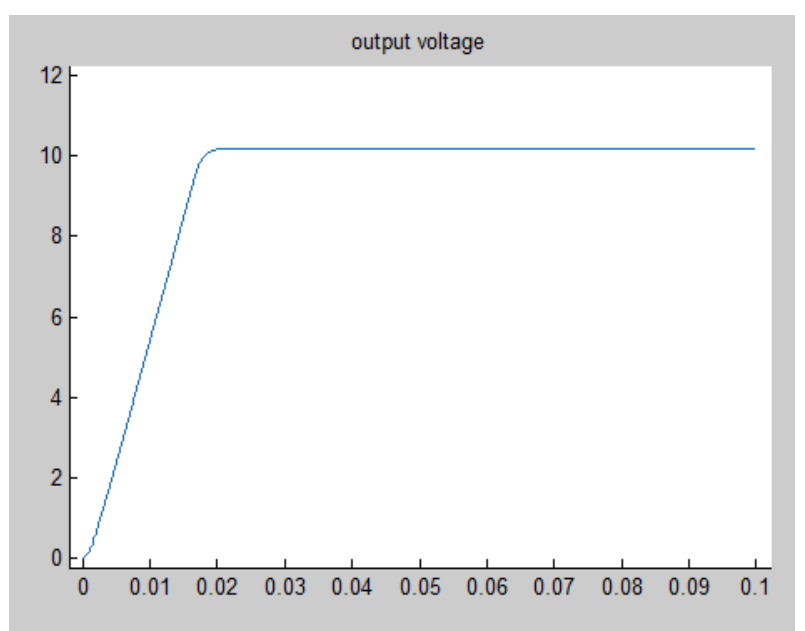

Fig. 7. (b) Output voltage waveform for single stage HB LLC

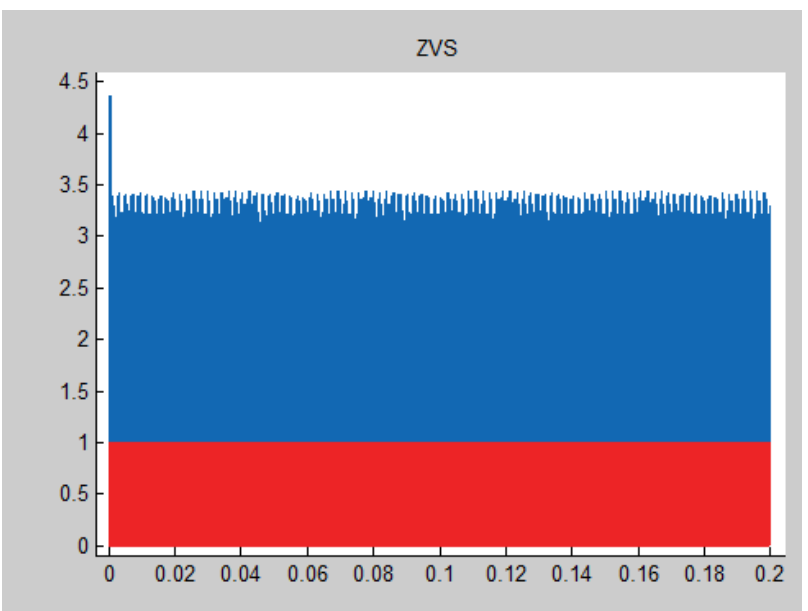

Fig. 8. ZVS of TS HBLLC

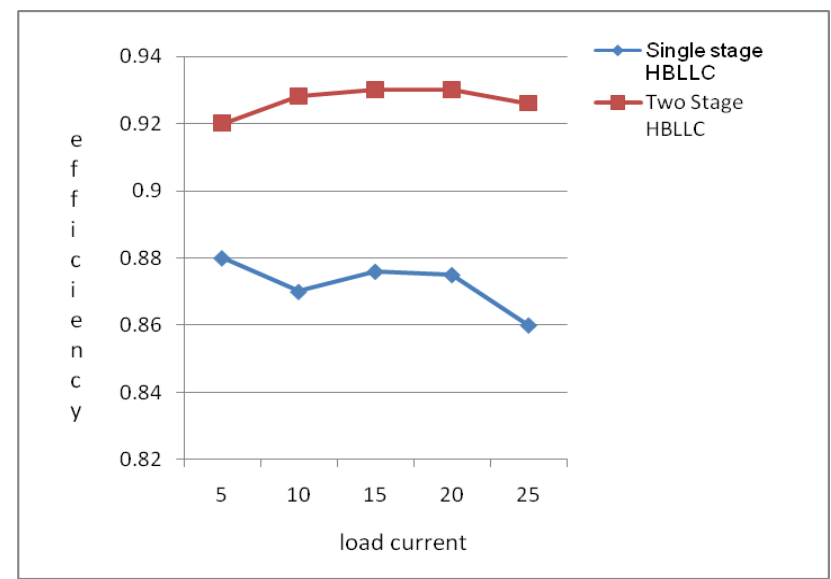

Fig. 9. Efficiency comparison of the converters

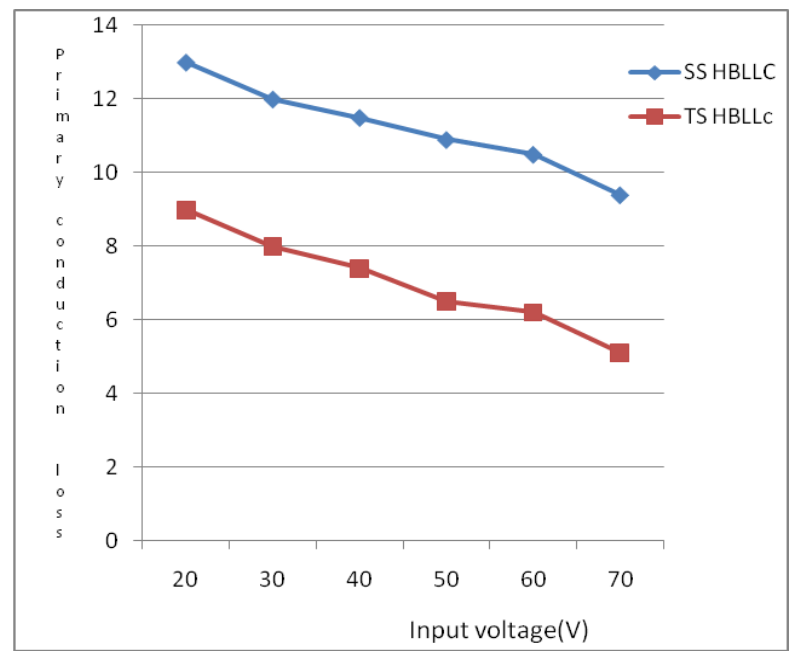

Fig 10 Comparison of primary conduction loss

When simulated at the nominal input voltage $48 \mathrm{~V}$ an output voltage of $11 \mathrm{~V}$ and output current of $24 \mathrm{~A}$ is obtained for SS HBLLC for rated 300W.The calculation of power density using the formula Efficiency $=\mathrm{P}_{\text {out }} /$ Volume of the converter shows that power density is less in TS HBLLC since the number of components in two stage converter is more.

Fig. 9 shows the comparison of the converters with load change which clearly evident two stage HB LLC is more efficient. In Fig 10 it is showed that conduction loss is less in two stage HB LLC.

The Fig.11 shows the comparison of both the converters since the number of components id less in single stage its cost is low comparatively.

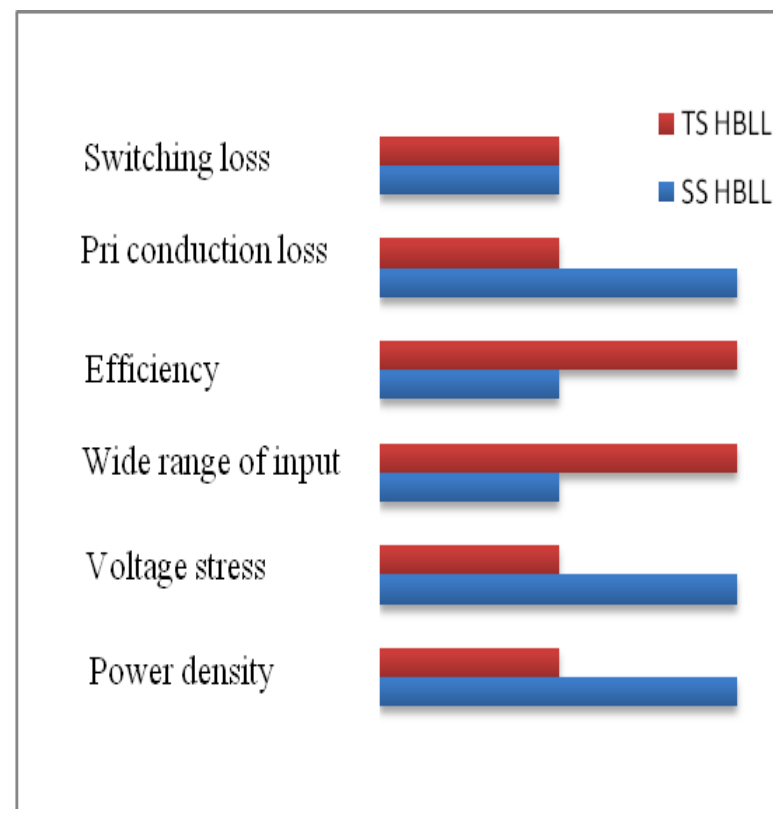

Fig. 11. Overall comparison the converters

\section{CONCLUSION}

In this paper the design specifications of single and two stage resonant converter. The 
waveforms are analyzed using simulation tool and the efficiency comparison is done. The results shows that the two stage HBLLC converter is more efficient and the performance is good.

\section{REFERENCES}

1. Y. Jeyashree, and Y.Sukhi, "LCC resonant converter with power factor correction for power supply units", Journal of the Chinese Institute of Engineers, Vol. 38, Issue 7, 2015, pp. 843-854.

2. Geetha Ramadas, Manoj Kumar Nadesan, Sukhi Yesuraj, and Jeyashree Yesuraj, "High power factor electronic ballast using resonant converter for compact fluorescent lamp", International Journal of Circuit Theory and Applications, Vol. 45, 2016, pp. 95-109.

3. Sukhi Y, and Y.Jeyashree, "Analysis and implementation of series -parallel resonant converter for regulated power supply", Journal of The institution of engineers (India), Vol. 90, Mar 2010.pp18-22.

4. Sukhi Yesuraj, Jeyashree Yesuraj, Perarasi Muthaiah, and Sarojini Balaraman "Standalone PV-fed LED Street Lighting Using Resonant Converter", Electric Power Components and Systems, 2017.

5. Y. Jang and M. M. Jovanovic, "A new soft-switched DCDC front-end converter for applications with wide-range input voltage from battery power sources," in Proc. 25th Telecommun. Energy Conf., Oct. 2003, pp. 770-777.

6. S. Luo and I. Batarseh, "A review of distributed power systems Part I: DC distributed power system," IEEE Aerosp. Electron. Syst. Mag., Vol. 20,Issue No. 8, Aug. 2005, pp. 5-16.

7. Sukhi Yesuraj, Geetha Ramadas, and Jeyashree Yesuraj, "High-Power-Factor Single-Switch AC to DC Converter for LED Lighting", IEEJ Transactions on Electrical and Electronic Engineering, Vol.12, No.6, 2016, pp.1-11.

8. Bo Yang, Fred C lee,Alpha J.Zhang,Guisong Huang "LLC Resonant converter for front end DC/DC conversion" in APEC. Seventeenth Annual IEEE Applied Power Electronics Conference and Exposition (Cat. No.02CH37335) March 2002.

9. Hong Huang "Designing an LLC resonant converter" Texas Instruments.

\section{AUTHORS PROFILE}

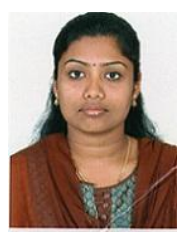

Jenifer A received the B.E. degree in the Electrical and Electronics Engineering from Tagore Engineering College in 2010 and the M.E. degree in Power Electronics and Drives from Jerusalem Engineering College in 2012.Currently working towards the Ph.D. degree at Anna University. She is currently an Assistant Professor in the Department of Electrical and Electronics Engineering at RMK Engineering College. Her main research interests include dc/dc converters, Electric Vehicles.

Sukhi Y received her B.E. Degree in Electrical and electronics Engineering

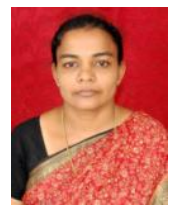
from Government College of Engineering / Madurai Kamaraj University in 1993. She obtained M.E in Mechatronics from Madras Institute of Technology, Anna University, Crompet in 2000. She obtained Ph.D in Electrical Engineering from Sathyabama University, Chennai in 2010. Presently she is working as an Professor, Department of Electrical and Electronics Engineering. R.M.K Engineering College. Chennai.

Tamilnadu, India.

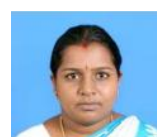

Karthika V received her B.E. Degree in Electrical and Electronics Engineering from Sri Muthukumaran Institute of Technology / Anna University in 2009. She obtained M.E in Control \& Instrumentation Engineering from Velammal Engineering college, Anna University in 2012. Presently she is working as an Assistant Professor, Department of Electrical and Electronics Engineering. R.M.K Engineering College. Chennai. Tamilnadu, India.

Fayaz Ahamed A received her B.E. Degree in Electrical and Electronics Engineering from ALAGAPPA Chettiar College of Engineering and Technology, Karaikudi / Madurai Kamaraj University in 2001. He obtained M.E in Power Electronics and Drives from College of Engineering Guindy, Anna University in 2010. Presently she is working

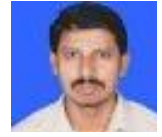

as an Assistant Professor, Department of Electrical and Electronics Engineering. R.M.K Engineering College. Chennai. Tamilnadu, India. 